\title{
DEVELOPMENT AND VALIDATION OF HPLC-DAD METHOD FOR THE DETERMINATION OF BISOPROLOL IN TABLET DOSAGE FORMS
}

\author{
YULIYA KONDRATOVA ${ }^{1}$, LILIYA LOGOYDA ${ }^{2 *}$, YULIIA VOLOSHKO ${ }^{1}$, AHMED ABDEL-MEGIED ${ }^{3}$, DMYTRO \\ KOROBKO ${ }^{2}$, YURIY SOROKA ${ }^{4}$
}

${ }^{1}$ Central R and D Laboratory JSC Farmak, Kyiv City Ukraine, ${ }^{2}$ Pharmaceutical Chemistry Department, Pharmaceutical Faculty, I. Horbachevsky Ternopil State Medical University, Ternopil City, Ukraine, ${ }^{3}$ Pharmaceutical Analytical Chemistry Department, Faculty of Pharmacy and Pharmaceutical Manufacturing, Kafrelsheikh University, Kafrelsheikh City, Egypt, ${ }^{4}$ Department of Anaesthesiology and Intensive-Care Medicine, I. Horbachevsky Ternopil State Medical University, Ternopil City, Ukraine Email: logojda@tdmu.edu.ua

Received: 26 Jul 2017, Revised and Accepted: 10 Oct 2017

\section{ABSTRACT}

Objective: A rapid, simple and sensitive RP-HPLC method was developed and validated for the determination of bisoprolol fumarate in bulk and pharmaceutical dosage form.

Methods: Chromatographic separation was achieved within 2.5 min on ACQUITY Arc System, Waters Symmetry C18 column (3.9 mm i.d. X 150 mm, $5 \mu \mathrm{m}$ particle sizes) using a mobile phase consisted of acetonitrile: phosphate buffer $(25: 75 \mathrm{v} / \mathrm{v})$ in an isocratic mode at a flow rate of $1.4 \mathrm{ml} / \mathrm{min}$. The $\mathrm{pH}$ of the mobile phase was adjusted to 7.0 with orthophosphoric acid and UV detection was set at $226 \mathrm{~nm}$.

Results: The retention time for bisoprolol fumarate was found to be 2.09 min. The proposed method was validated according to ICH guidelines with respect to linearity, specificity precision, accuracy and robustness. The limit of detection and limit of quantification are calculated and found to be 0.4825 and $1.4621 \mu \mathrm{g} / \mathrm{ml}$; respectively.

Conclusion: The proposed method can help research studies, quality control and routine analysis with lesser resources available. The results of the assay of pharmaceutical formulation of the developed method are highly reliable and reproducible and is in good agreement with the label claim of the medicines.

Keywords: Bisoprolol, High-Performance Liquid Chromatography, Validation, ICH guidelines

(C) 2017 The Authors. Published by Innovare Academic Sciences Pvt Ltd. This is an open access article under the CC BY license (http://creativecommons.org/licenses/by/4.0/) DOI: http://dx.doi.org/10.22159/ijap.2017v9i6.21616

\section{INTRODUCTION}

Nowadays in the pharmaceutical analysis is dominated by physicochemical methods of analysis, the most reliable of which are methods of chromatographic analysis. Chromatographic methods allow to carry out qualitative and quantitative determination of AFI.

Bisoprolol is a synthetic, beta1-selective (cardioselective) adrenoceptor blocking agent without significant membrane stabilizing activity or intrinsic sympathomimetic activity in its therapeutic dosage range. The chemical name of bisoprolol fumarate is 1-(propan-2ylamino)-3-[4-(2-propan-2-yloxyethoxymethyl) phenoxy] propan-2-ol (fig. 1). The two substituents present in the para position of the benzene ring might be the reason for its $\beta 1$-adrenergic receptor selectivity. The most prominent effect of bisoprolol fumarate is the negative chronotropic effect, resulting in a reduction in resting and exercise heart rate. There is a fall in resting and exercise cardiac output with little observed change in stroke volume, and only a small increase in right atrial pressure, or pulmonary capillary wedge pressure at rest or during exercise [1].<smiles>CC(C)NCC(O)COc1ccc(COCCOC(C)C)cc1</smiles>

Fig. 1: Chemical structure of bisoprolol fumarate

A literature survey was conducted and several methods were reported for the determination of bisoprolol fumarate, such as spectrophotometry [2-5] and liquid chromatography [6-12].
However, no rapid and sensitive HPLC for the determination of bisoprolol in its tablet dosage form.

This novel proposed method contributes quick estimation, correct peak shape, precise, simple, and quick, use of smaller sample volumes and acetonitrile and phosphate buffer solution $\mathrm{pH} 7.0$ as a mobile phase which is economical when compared with other existing methods [13].

The present work aimed to develop a simple, rapid, sensitive and specific method for the determination of bisoprolol fumarate in its tablet dosage form according to ICH guidelines Q2 (R1) [14].

\section{MATERIALS AND METHODS}

\section{Chemicals and reagents}

Bisoprolol fumarate was obtained as a gift from Farmak pharmaceuticals (Kiev, Ukraine). HPLC grade acetonitrile, triethylamine, ammonium phosphate, orthophosphoric acid were obtained from Merck pharamaceticals.

\section{Instrumentation and chromatographic conditions}

ACQUITY Arc System, Waters Symmetry C18 column (3.9 mm i.d. X $150 \mathrm{~mm}, 5 \mu \mathrm{m})$. Chromatographic separation was carried out at ambient temperature $\left(22^{\circ} \mathrm{C}-25^{\circ} \mathrm{C}\right)$. The compound was separated isocratically with a mobile phase consisting of acetonitrile and phosphate buffer solution $\mathrm{pH} 7.0(25 / 75, v / v)$ at a flow rate 1.4 $\mathrm{ml} / \mathrm{min}$ with injection volume $10 \mu \mathrm{L}$. The effluent was monitored spectrophotometrically at wavelength $226 \mathrm{~nm}$.

\section{Preparation of mobile phase}

To prepare phosphate buffer solution $\mathrm{pH} 7.0 .: 6.60 \mathrm{~g}$ of ammonium phosphate dissolve in $980 \mathrm{ml}$ of water, add $2.0 \mathrm{ml}$ of triethylamine, fix the $\mathrm{pH}$ of the solution to the value $(7.0 \pm 0.05)$ with phosphoric acid, and then add the volume of the solution with water $\mathrm{P}$ to 1000.0 $\mathrm{ml}$ and mix. 


\section{Stock standard solutions}

Primary stock solutions of bisoprolol fumarate was prepared daily separately by dissolving $25 \mathrm{mg}$ of each in $250 \mathrm{ml}$ volumetric flasks ( 0.1 $\mathrm{mg} / \mathrm{ml}$ ) in mobile phase. Limits of the range of application of the procedure were determined from $70 \%$ to $130 \%$ to the nominal concentration of bisoprolol fumarate $(0.1 \mathrm{mg} / \mathrm{ml})$ in the test solution.

\section{Procedures}

The standard solutions were prepared by dilution of the stock standard solution with mobile phase. Triplicate $20.0 \mu \mathrm{L}$ injections were made for each concentration and chromatographed under the condition described above. The peak area of each concentration was plotted against the corresponding concentration to obtain the calibration graph and regression equation was computed.

\section{Analysis of dosage form}

Accurately weighed twenty bisoprolol tablets and average weight was calculated. Accurately weighed a portion of tablet, powder equivalent to $10 \mathrm{mg}$ of bisoprolol fumarate and transfer into a 100 $\mathrm{ml}$ volumetric flask to this $50 \mathrm{ml}$ solvent (water-acetonitrile 80:20 $\mathrm{v} / \mathrm{v}$ ) was added and sonicated for $15 \mathrm{~min}$. Solvent (wateracetonitrile $80: 20 \mathrm{v} / \mathrm{v}$ ) was adjusted up to the mark. The solution was filtered using $0.45 \mu \mathrm{m}$ nylon filter. The amount present in the tablet was calculated from plotted calibration graph or utilizing regression equation. After setting the chromatographic conditions and stabilizing the instrument to obtain a steady baseline, the sample solution was loaded in the $10 \mu$ lixed sample loop of the injection port.

\section{Method validation}

Once the chromatographic and the experimental conditions were established, the method was validated with respect to specificity, linearity, precision, accuracy, robustness, limit of detection (LOD), limit of quantitation (LOQ) according to ICH Q2 (R1) guidelines [15, 16].

\section{System suitability parameters}

The chromatographic systems used for analysis must pass system suitability before going to start the experiment. At first HPLC system is stabilized for forty minutes. Inject blank preparation (single injection) and standard preparation (six replicates) and record the chromatograms to evaluate the system suitability parameters such as tailing factor, theoretical plate count and retention time. The parameters such as tailing factor, \% RSD and theoretical plates were studied.

\section{Linearity}

A standard stock solution of the bisoprolol fumarate $(0.1 \mathrm{mg} / \mathrm{ml})$ was prepared with the mobile phase. To study the linearity range of drugs, serial dilutions were made from standard stock solution.

\section{Specificity}

Specificity of an analytical method is its ability to measure accurately and specifically the analyte of interest without interference from placebo and degradation products. The specificity of the method was established by injecting blank, placebo and standard solution in triplicate and recording the chromatograms.

\section{Precision}

The precision of the method was determined by repeatability (intraday) and intermediate precision (interday). Repeatability was determined by performing six repeated analysis of the same working solution of bisoprolol fumarate on the same day, under the same experimental conditions. The intermediate precision of the method was assessed by carrying out the analysis on different days and also by another analyst performing the analysis in the same laboratory (between-analysts).

\section{Accuracy}

The accuracy of a method is defined as the closeness of a measured value to the true value. The recovery studies were carried out at 70 $130 \%$ of the target level in the tablet in triplicate each in the presence of placebo.

\section{Robustness}

The robustness was determined by analyzing the same sample under a variety of conditions. The factors considered to be: variations in the flow rate, detection wavelength and mobile phase composition. There were no significant changes in the chromatographic pattern when the above modifications were made in the experimental conditions, showing thus that the method is robust. The \% RSD of bisoprolol fumarate should be not more than $2.0 \%$.

\section{LOD and LOQ}

Limit of detection is the lowest concentration in a sample that can be detected, but not necessarily quantified under the stated experimental conditions. The limit of quantitation is the lowest concentration of analyte in a sample which can be quantitatively determined with suitable precision and accuracy.

\section{RESULTS AND DISCUSSION}

\section{Method development and optimization}

The RP-HPLC method was developed to provide specific procedure for the rapid quality control analysis of bisoprolol fumarate. To find the appropriate HPLC conditions for separation of the examined drug, various reversed phase columns, isocratic and gradient mobile phase systems were tried, and successfully attempts were performed using a RP-C18 chromatographic column Symmetry C18 column ( $3.9 \mathrm{~mm}$ i.d. X $150 \mathrm{~mm}, 5 \mu \mathrm{m})$ and mobile phase composed of acetonitrile: phosphate buffer solution $\mathrm{pH} 7.0$ in the ratio of 25:75 $\mathrm{v} / \mathrm{v}$, at a flow rate of $1.4 \mathrm{ml} / \mathrm{min}$ with $\lambda_{\max }$ at $226 \mathrm{~nm}$. Under the described HPLC parameters, the respective compound was clearly separated and their corresponding peaks were sharply developed at reasonable Rt 2.09 min as shown in (fig. 2). Previous studies show more Rt than 2.09 and it means that developed method is more rapid [6-13]. The optimum chromatographic conditions and system suitability parameters are tabulated in table 1.

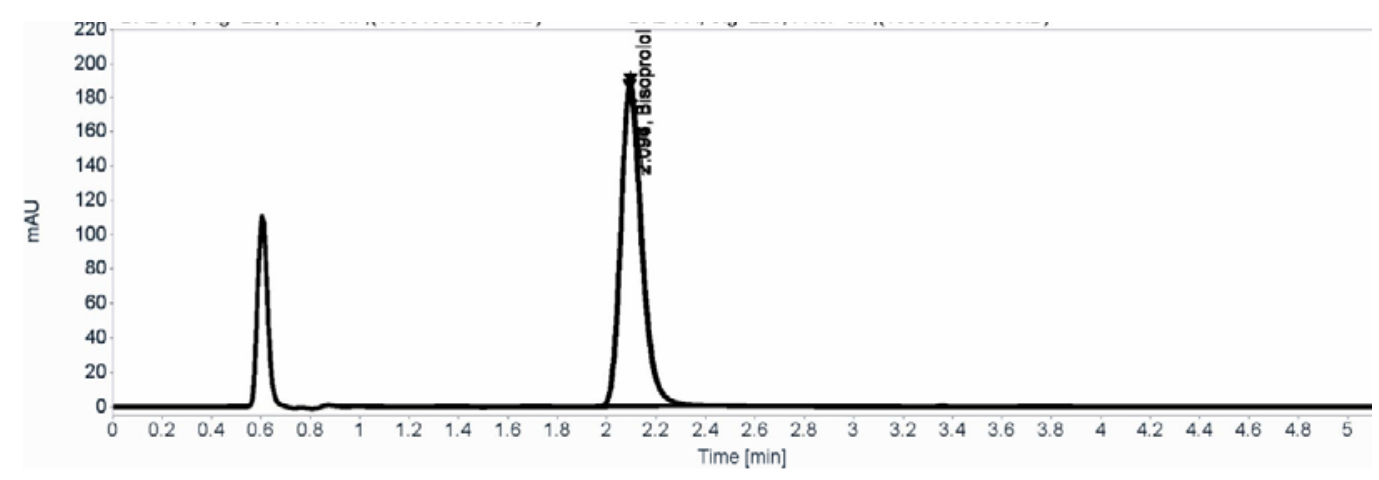

Fig. 2: Representative chromatogram of USP bisoprolol fumarate $(0.1 \mathrm{mg} / \mathrm{ml})$ using UV detection at $226 \mathrm{~nm}$ 
Table 1: Optimized chromatographic conditions

\begin{tabular}{ll}
\hline Parameter & Chromatographic conditions \\
\hline Instrument & ACQUITY Arc System \\
Column & Waters Symmetry C18 column $(3.9 \mathrm{~mm}$ i.d. X $150 \mathrm{~mm}, 5 \mu \mathrm{m})$ \\
Mobile phase & Acetonitrile: phosphate buffer solution pH $7.0(25 / 75, \mathrm{v} / \mathrm{v})$ \\
Flow rate & $1.4 \mathrm{ml} / \mathrm{min}$ \\
Detection wavelength & $\mathrm{UV}$ at $226 \mathrm{~nm}$ \\
Runtime & $10 \mathrm{~min}$ \\
Column temperature & $35^{\circ} \mathrm{C}$ \\
Volume of injection loop & $10 \mu \mathrm{l}$ \\
Retention time & $2.09 \mathrm{~min}$ \\
\hline
\end{tabular}

$*=$ number of 5 determinations.

\section{System suitability}

According to U. S. Pharmacopeia (USP) states that system suitability tests are an integral part of liquid chromatographic methods. They are used to verify that the resolution and reproducibility of the chromatographic system are adequate for the analysis to be done.
For HPLC method, it was used to verify that the column efficiency (N), selectivity factor (resolution) and reproducibility of the chromatographic system. Parameters including resolution (Rs), peak symmetry, capacity factor $\left(K^{\prime}\right)$ and selectivity factor $(\alpha)$ were calculated, as shown in table 2 . All the values are well within the limit.

Table 2: Analytical parameters for system suitability test of HPLC

\begin{tabular}{lll}
\hline Parameters & Reference & Bisoprolol fumarate \\
\hline Retention time (min) & ------ \\
Resolution (R) & $\mathrm{R}>2$ & $>1$ \\
Selectivity factor $(\alpha)$ & $0.1-10$ acceptable \\
K' (Column capacity) & - \\
Symmetry & $\leq 2$ & 1.12 \\
Tailing Factor (T) & Increases with efficiency of the separation \\
N (column efficiency) & The smaller the value, the higher the column efficiency =L/N \\
Height equivalent theoretical plates (HETP) & 0.012 \\
\hline
\end{tabular}

\section{Method validation}

\section{Linearity}

Calibration curve representing the relation between the concentrations of drugs versus the peak area were constructed. In triplicate run from which the linear regression equation was calculated. The results of chromatographic determination of nine model solutions of bisoprolol fumarate are present in table 3. The calibration plot of bisoprolol fumarate is presented in (fig. 3) and characteristics of the linear dependence of bisoprolol fumarate are listed in table 4 .

The results show that a phenomenal relationship between peak area and concentration of the drug in the calibration curve.

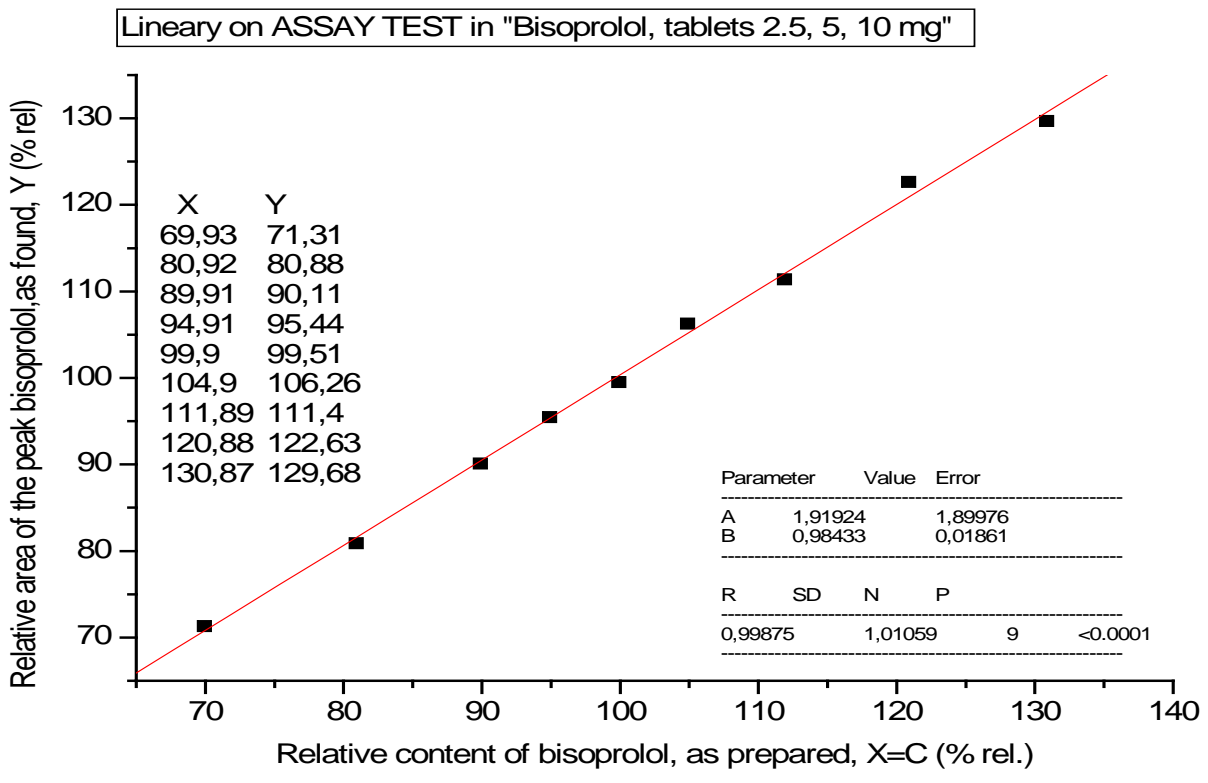

Fig. 3: The calibration graph of bisoprolol fumarate 
Table 3: Chromatographic determination of model solutions of bisoprolol fumarate

\begin{tabular}{|c|c|c|c|c|c|}
\hline $\begin{array}{l}\text { Model } \\
\text { solutions } \\
\end{array}$ & Assigned API content, $X_{i}(\%)$ & $\begin{array}{l}S_{\mathrm{i}} \\
\text { parallel measurements }\end{array}$ & Average $S_{i}$ & RSD $_{i,}, \%$ & Found content of $A P I, Y_{i}(\%)$ \\
\hline \multirow[t]{5}{*}{1} & 69.93 & 774.132 & 774.241 & 0.03 & 71.31 \\
\hline & & 774.227 & & & \\
\hline & & 774.029 & & & \\
\hline & & 774.594 & & & \\
\hline & & 774.221 & & & \\
\hline \multirow[t]{5}{*}{2} & 80.92 & 879.099 & 878.074 & 0.13 & 80.88 \\
\hline & & 878.136 & & & \\
\hline & & 879.243 & & & \\
\hline & & 877.213 & & & \\
\hline & & 876.681 & & & \\
\hline \multirow[t]{5}{*}{3} & 89.91 & 978.703 & 978.326 & 0.11 & 90.11 \\
\hline & & 976.504 & & & \\
\hline & & 978.890 & & & \\
\hline & & 978.484 & & & \\
\hline & & 979.049 & & & \\
\hline \multirow[t]{5}{*}{4} & 94.91 & 1036.698 & 1036.192 & 0.16 & 95.44 \\
\hline & & 1037.089 & & & \\
\hline & & 1033.310 & & & \\
\hline & & 1036.406 & & & \\
\hline & & 1037.456 & & & \\
\hline \multirow[t]{5}{*}{5} & 99.90 & 1080.720 & 1080.323 & 0.03 & 99.51 \\
\hline & & 1079.984 & & & \\
\hline & & 1080.441 & & & \\
\hline & & 1080.173 & & & \\
\hline & & 1080.298 & & & \\
\hline \multirow[t]{5}{*}{6} & 104.90 & 1153.316 & 1153.601 & 0.04 & 106.26 \\
\hline & & 1154.312 & & & \\
\hline & & 1153.254 & & & \\
\hline & & 1153.666 & & & \\
\hline & & 1153.455 & & & \\
\hline \multirow[t]{5}{*}{7} & 111.89 & 1209.429 & 1209.479 & 0.06 & 111.40 \\
\hline & & 1209.652 & & & \\
\hline & & 1209.619 & & & \\
\hline & & 1210.412 & & & \\
\hline & & 1208.281 & & & \\
\hline \multirow[t]{5}{*}{8} & 120.88 & 1332.491 & 1331.349 & 0.06 & 122.63 \\
\hline & & 1330.725 & & & \\
\hline & & 1331.603 & & & \\
\hline & & 1331.185 & & & \\
\hline & & 1330.739 & & & \\
\hline \multirow[t]{9}{*}{9} & 130.87 & 1407.595 & 1407.951 & 0.05 & 129.68 \\
\hline & & 1409.233 & & & \\
\hline & & 1407.299 & & & \\
\hline & & 1407.680 & & & \\
\hline & & 1407.949 & & & \\
\hline & & 1086.486 & & & \\
\hline & & 1085.791 & & & \\
\hline & & 1084.526 & & & \\
\hline & & 1085.396 & & & \\
\hline
\end{tabular}

*Average of triplicate injections

Table 4: Characteristics of the linear dependence of bisoprolol fumarate

\begin{tabular}{lll}
\hline The name of the quantity & Value & Criteria for the parameters of linear dependence (according to SPU 1.2, p. 85) \\
\hline$B$ & 0.98433 & \\
$S_{B}$ & 0.01861 & \\
$A$ & 1.91924 & $\leq 2.56$ \\
$S_{A}$ & 1.89976 & \\
$S_{R}$ & 1.01059 & \\
$S_{R} / B$ & 1.02614 & $\leq 1.27$ \\
$R$ & 0.99875 & $\geq 0.997789$ \\
\hline
\end{tabular}

The results obtained were processed by the least squares method. The correlation coefficient of bisoprolol fumarate $\left(\mathrm{r}^{2}\right)$ was noted as 0.99875 which states that the method was good linear to the concentration versus peak area responses. Results indicate high sensitivity of the proposed HPLC method.

\section{Specificity}

Commonly used tablet excipients did not interfere with the proposed method. The specificity results are tabulated in table 5. Furthermore, the well shaped peaks also indicate the specificity of the method. 
Table 5: Specificity study

\begin{tabular}{ll}
\hline Name of the solution & Retention time $\left(\mathbf{t}_{\mathbf{R}}\right) \mathbf{m i n}$ \\
\hline mobile phase & No peaks \\
placebo & No peaks \\
bisoprolol fumarate $0.5 \mathrm{mg} / \mathrm{ml}$ & 2.09 \\
\hline
\end{tabular}

\section{Accuracy and precision}

Intra-day and inter-day precision represented as \% RSD values lower than $2 \%$ clearly assuring that this method was found to be fairly precise and reproducible as shown in Tables 6,7. The standard addition method was performed at $70 \%, 80 \%, 90 \%, 100 \%, 110 \%$, $120 \%, 130 \%$ levels as illustrated in table 8. \% RSD was lower than $2 \%$ proving the high repeatability of the new method.

Table 6: Results of system precision

\begin{tabular}{llll}
\hline Sample & Concentration $(\boldsymbol{\mu g} / \mathbf{m l})$ & Peak area & Injection no. \\
\hline Bisoprolol & 0.1 & 1086.213 & 1 \\
& & 1086.486 & 2 \\
& 1085.791 & 3 & 0.07 \\
& & 1084.526 & 4 \\
& 1085.396 & 5 & \\
\end{tabular}

*Each value is represented as a mean \pm SD of 4 observations $(n=4)$, SD: Standard Deviation, RSD: Relative Standard Deviation, \#Acceptance criteria $<2.0$.

Table 7: Intra-day and Inter-day precision data of bisoprolol fumarate

\begin{tabular}{|c|c|c|c|c|}
\hline \multirow[t]{2}{*}{ Day } & \multicolumn{2}{|c|}{ Intra-day precision } & \multicolumn{2}{|c|}{ Inter-day precision } \\
\hline & Mean & RSD \% & Mean & RSD \% \\
\hline 1 & 99.82 & 0.311 & 100.76 & 0.364 \\
\hline 2 & 100.41 & 0.647 & 99.27 & 0.390 \\
\hline 3 & 100.82 & 0.336 & 100.53 & 0.572 \\
\hline
\end{tabular}

*Each value is represented as a mean \pm SD of observations, SD: Standard Deviation, RSD: Relative Standard Deviation, \#Acceptance criteria $<2.0$

Table 8: Evaluation of accuracy of the proposed HPLC method

\begin{tabular}{|c|c|c|c|}
\hline \multirow{2}{*}{$\begin{array}{l}\text { Model } \\
\text { solutions }\end{array}$} & \multicolumn{2}{|l|}{ The amount of bisoprolol fumarate, $\%$} & \multirow{2}{*}{$\begin{array}{l}\text { Found,\% to predetermined, } \\
Z_{i}=\left(Y_{i} / X_{i}\right) \cdot 100 \%\end{array}$} \\
\hline & Predetermined quantity, $X_{i}=\left(m_{i} / m_{r s}\right) 100 \%$ & Found quantity, $Y_{i}=\left(S_{i} / S_{r s}\right) 100 \%$ & \\
\hline 1 & 69.93 & 71.31 & 101.98 \\
\hline 2 & 80.92 & 80.88 & 99.95 \\
\hline 3 & 89.91 & 90.11 & 100.22 \\
\hline 4 & 94.91 & 95.44 & 100.56 \\
\hline 5 & 99.90 & 99.51 & 99.60 \\
\hline 6 & 104.90 & 106.26 & 101.30 \\
\hline 7 & 111.89 & 111.40 & 99.56 \\
\hline 8 & 120.88 & 122.63 & 101.44 \\
\hline 9 & 130.87 & 129.68 & 99.09 \\
\hline \multicolumn{3}{|c|}{ Average, $Z, \%$} & 100.41 \\
\hline \multicolumn{3}{|c|}{ Standard deviation, $S_{z,} \%$} & 0.98 \\
\hline \multicolumn{3}{|c|}{ Confidence interval of convergence of results (actual) } & 1.82 \\
\hline \multicolumn{4}{|c|}{$\Delta=t(95 \%, 8) \cdot S_{z}=1.8595 \cdot S_{z} \%$} \\
\hline \multicolumn{3}{|c|}{ Critical value for the convergence of results } & Performed \\
\hline \multicolumn{3}{|c|}{$\Delta \leq \max \Delta_{A s}=2.4 \%$} & $(1.82<2.4)$ \\
\hline \multicolumn{3}{|c|}{ Systematic error $\delta=|Z-100|, \%$} & 0.41 \\
\hline \multicolumn{3}{|c|}{ Criterion of significance of systematic error } & Performed \\
\hline \multicolumn{3}{|c|}{$\delta \leq \max \delta \%$} & $(0.41<0.77)$ \\
\hline \multicolumn{3}{|c|}{ The general conclusion about the technique: } & Correct \\
\hline
\end{tabular}

*Average of triplicate injections

Regarding accuracy, a known amount of the standard drug was added to the fixed amount of preanalyzed sample solution. The percentage recovery was calculated by comparing the area before and after addition of the standard drug. These data showed that the proposed method was both accurate and precise for the determination of bisoprolol fumarate in medicines. The high value of recoveries obtained for bisoprolol indicates that the proposed method was found to be accurate.

\section{LOD and LOQ}

The LOD and LOQ values are presented in table 9.

\section{Table 9: LOD and LOQ of the proposed HPLC method for bisoprolol fumarate}

\begin{tabular}{lr}
\hline Limit of Detection (LOD) & $0.4825 \mu \mathrm{g} / \mathrm{ml}$ \\
Limit of Quantitation (LOQ) & $1.4621 \mu \mathrm{g} / \mathrm{ml}$ \\
\hline
\end{tabular}

The developed method found to be high sensitivity with LOD and LOQ of 0.4825 and $1.4621 \mu \mathrm{g} / \mathrm{ml}$; respectively. The results of LOD and LOQ supported the sensitivity of the proposed method. 
Table 10: Robustness of the proposed HPLC method for bisoprolol fumarate

\begin{tabular}{|c|c|c|c|c|}
\hline Parameter & Optimized & Used & Retention time (min) & Remark \\
\hline \multirow[t]{3}{*}{ Flow rate $( \pm 0.2 \mathrm{ml} / \mathrm{min})$} & $1.4 \mathrm{ml} / \mathrm{min}$ & $1.2 \mathrm{ml} / \mathrm{min}$ & 2.11 & Robust \\
\hline & & $1.4 \mathrm{ml} / \mathrm{min}$ & 2.09 & Robust \\
\hline & & $1.6 \mathrm{ml} / \mathrm{min}$ & 2.09 & Robust \\
\hline \multirow[t]{3}{*}{ Detection wavelength $( \pm 5 \mathrm{~nm})$} & $226 \mathrm{~nm}$ & $221 \mathrm{~nm}$ & 2.10 & Robust \\
\hline & & $226 \mathrm{~nm}$ & 2.09 & Robust \\
\hline & & $231 \mathrm{~nm}$ & 2.11 & Robust \\
\hline Mobile phase composition & $25: 75 \mathrm{v} / \mathrm{v}$ & $30: 70 \mathrm{v} / \mathrm{v}$ & 2.12 & Robust \\
\hline \multirow{2}{*}{ (acetonitrile: phosphate buffer solution pH 7.0) ( $\pm 0.5 \%$ ) } & & $25: 75 \mathrm{v} / \mathrm{v}$ & 2.09 & Robust \\
\hline & & $20: 80 \mathrm{v} / \mathrm{v}$ & 2.11 & Robust \\
\hline
\end{tabular}

It was evaluated by small deliberate changes in method parameters such as flow rate $( \pm 0.2 \mathrm{ml} / \mathrm{min})$, detection wavelength $( \pm 5 \mathrm{~nm})$ and mobile phase composition $( \pm 0.5 \%)$. The \% RSD values of robustness which is less than $2 \%$ reveals that the proposed method is robust. The results of robustness indicate that even though the small changes in the conditions did not significantly effect on retention time of bisoprolol fumarate.

Table 11: Results of analysis of bisoprolol fumarate

\begin{tabular}{|c|c|c|c|c|c|}
\hline S. No & Formulation & Labelled amount, mg/tablet & Amount found, mg/tablet & Mean $\%$ assay \pm SD & \% RSD \\
\hline 1 & Bisoprolol tablets & 5 & 4.98 & $99 \pm 1$ & 0.100 \\
\hline
\end{tabular}

*Average of 5 determinations; SD: standard deviation; RSD: relative standard deviation.

\section{Robustness}

The results of robustness study results are shown in table 10.

\section{Tablet analysis}

The developed, validated method was successfully applied for the determination of bisoprolol fumarate in their tablet dosage form. The assay result shows that the amount of the drug was in excellent agreement with the labelled value of the formulation as illustrated in table 11.

\section{CONCLUSION}

In conclusion, a rapid, simple, accurate, sensitive and precise HPLC method was developed and validated for the estimation of bisoprolol fumarate in its tables dosage form. Statistical analysis for the above results obviously demonstrates that the method is fit for the estimation of bisoprolol fumarate in tablet forms without any interference. The proposed method can help research studies, quality control and routine analysis with lesser resources available. The results of the assay of pharmaceutical formulation of the developed method are highly reliable and reproducible and is in good agreement with the label claim of the drug.

\section{CONFLICT OF INTERESTS}

\section{Declared none}

\section{REFERENCES}

1. http://www.druglib.com [Last accessed on 20 Jun 2017].

2. Ulu ST, Kel E. Spectrophotometric determination of bisoprolol in pharmaceutical preparations by charge transfer reactions. Opt Spektrosk 2012;112:864-7.

3. Kumbhar ST, Shinde PP, Shinde DB, Solankar PB. Visible spectrophotometric method for estimation of bisoprolol from its bulk and tablet formulation. Asian J Pharm Clin Res 2013;6:103-5.

4. Kakde RB, Kotak VH, Barsagade AG, Chaudhary NK, Kale DL Spectrophotometric method for simultaneous estimation of amlodipine besylate and bisoprolol fumarate în pharmaceutical preparations. Res J PharmTech 2008;1:513-5.

5. Sahu R, Patel VB. Simultaneous spectrophotometric estimation of hydrochlorothiazide and bisoprolol fumarate in combined dosage forms. Indian J Pharm Sci 2006;68:764-7.
6. Arjun G, Sathis KD, Bindu MB, Naga MM, Ramalingam R, RavinderNath A. A simple HPLC method for quantitation of bisoprolol fumarate in tablet dosage form. Indian Drugs 2009;46:39-42.

7. Yadav SS, Rao JR. Simultaneous HPTLC analysis of bisoprolol fumarate and hydrochlorthiazide in pharmaceutical dosage form. Int J Pharm Pharm Sci 2013;5:286-90.

8. Joshi SJ, Karbhari PA, Bhoir SI, Bindu KS, Das C. RP-HPLC method for simultaneous estimation of bisoprolol fumarate and hydrochlorothiazide in tablet formulation. J Pharm Biomed Anal 2010;52:362-71.

9. Shaikh S, Thusleem OA, Muneera MS, Akmal J, Kondaguli AV, Ruckmani K. A simple and rapid high-performance liquid chromatographic method for the determination of bisoprolol fumarate and hydrochlorothiazide in a tablet dosage form. J Pharm Biomed Anal 2008;48:1055-7.

10. Patel LJ, Suhagia BN, Shah PB, Shah RR. Simultaneous estimation of bisoprololfumarate and hydrochlorothiazide in tablet dosage form by RP-HPLC method. Indian J Pharm Sci 2006;68:635-8.

11. Vora D, Kadav A. Development and validation of a simultaneous HPLC method for estimation of bisoprolol fumarate and amlodipine besylate from tablets. Indian J Pharm Sci 2008;70:542-6.

12. Bozal B, Gumustas M, Dogan-Topal B, Uslu B, Ozkan SA. Fully validated simultaneous determination of bisoprololfumarate and hydrochlorothiazide in their dosage forms using different voltammetric, chromatographic, and spectrophotometric analytical methods. J AOAC Int 2013;96:42-51.

13. Raul SK, Aravelli AB, Jhansi D. RP-HPLC method development and validation for the simultaneous estimation of atorvastatin and ezetimibe in pharmaceutical dosage form. Asian J Pharm Clin Res 2015;8:178-81.

14. ICH Q2 (R1), Validation of analytical procedures, Text and methodology. International Conference on Harmonization, Geneva; 2005. p. 1-17.

15. Patel R, Patel M, Dubey N, Dubey N, Patel B. HPTLC method development and validation: strategy to minimize methodological failures. J Food Drug Anal 2012;20:561-71.

16. Ravisankar P, Naga Navya Ch, Pravallika D, Navya Sri D. A review on step-by-step analytical method validation. IOSR J Pharm 2015;5:7-19. 